\title{
Surface Chemistry of $\mathrm{CH}_{3} \mathrm{Br}$ and Methyl Modified by Copper Deposition on $\mathrm{Ru}(001)$
}

\author{
T. Livneh ${ }^{\dagger}$ and M. Asscher* \\ Department of Physical Chemistry and the Farkas Center for Light Induced Processes, The Hebrew University, \\ Jerusalem 91904, Israel
}

Received: December 3, 1998; In Final Form: March 18, 1999

\begin{abstract}
The chemistry of methyl bromide on $\mathrm{Cu} / \mathrm{Ru}(001)$ has been studied utilizing work function change $(\Delta \varphi)$ and temperature-programmed desorption (TPD) measurements. The remarkable modification in the methyl fragments dehydrogenation at the completion of a single copper layer and the significant difference in reactivity of the $\mathrm{Cu}(2 \mathrm{ML}) / \mathrm{Ru}(001)$ or $\mathrm{Cu}(111)$ surfaces are the focus of this study. A decrease in work function at the completion of $1 \mathrm{ML} \mathrm{CH}_{3} \mathrm{Br}$ of $2.15 \pm 0.02 \mathrm{eV}$ and $1.33 \pm 0.05 \mathrm{eV}$ was measured, respectively, for $\mathrm{Ru}(001)$ and $\mathrm{Cu}(2 \mathrm{ML}) / \mathrm{Ru}(001)$ held at $82 \mathrm{~K}$. Methyl bromide does not dissociate upon adsorption on clean or the copper-covered surfaces, and it is bound with the bromine down. Copper modifies the reactivity of the Ru substrate, gradually decreasing the dissociated fraction of $\mathrm{CH}_{3} \mathrm{Br}$ from 0.55 of the initial one monolayer on clean $\mathrm{Ru}(001)$ to 0.06 on $\mathrm{Cu}(2 \mathrm{ML}) / \mathrm{Ru}(001)$, probably because of defects in the copper layer. The methyl fragment dehydrogenation rate slows as the copper coverage increases. At a narrow copper coverage range between 0.8 and $0.95 \mathrm{ML}$, adsorbed hydrogen and methyl fragments coexist on the surface in the temperature range 230-280 K. Sequential decomposition channels of the parent molecules and the methyl fragment lead to a unique enhancement of methane production rate, this on the account of further hydrocarbon dehydrogenation, as reflected in both $\Delta p$ and $\Delta \varphi$ TPD measurements. Methane is formed on top of copper terraces as a result of "spill-over" of both methyl and hydrogen atoms, similar to the chemistry over $\mathrm{Cu}(111)$ and $\mathrm{Cu}(110)$ single-crystal surfaces. The dipole moment of adsorbed methyl is reported here for the first time on metal surfaces, being $0.48 \mathrm{D}$ on top of $\mathrm{Cu}(2 \mathrm{ML}) / \mathrm{Ru}(001)$.
\end{abstract}

\section{Introduction}

Interest in bimetallic catalysts had been motivated by the commercial success of these systems. This success results from the improved ability to control the catalytic activity and selectivity by tailoring the catalyst's composition. One of the most extensively investigated bimetallic systems is $\mathrm{Cu} / \mathrm{Ru} .^{1-4}$ $\mathrm{Cu} / \mathrm{Ru}$ catalysts have been used to control catalytic activity and selectivity in the Fischer-Tropsch reaction. ${ }^{1,3,5,6}$ The addition of $\mathrm{Cu}$ to $\mathrm{Ru}$ induces formation of longer chains of alkane. ${ }^{3}$

A key issue in these studies is the relative role of "ligand" (electronic) vs "ensemble" (morphological) effects in identifying the catalytic behavior. Ensemble effect is often associated with a simple blocking of sites adjacent to the active one. By reduction of the number of vacant sites, the surface is deactivated. Reactions that require a large ensemble of active sites can be selectively suppressed, leaving only small ensemble reactions. In the case of $\mathrm{Cu} / \mathrm{Ru}(001)$ at $300 \mathrm{~K}$ copper forms islands ${ }^{7-9}$ and blocks the chemisorption of both $\mathrm{H}_{2}{ }^{10}$ and $\mathrm{CO}^{11,12}$ on the $\operatorname{Ru}(001)$ surface.

Formation of the bond between the two different metals leads to electron polarization toward the element with the larger fraction of empty states in its valence band and is accompanied by a large perturbation in the electronic properties of the metals. The resulting electronic modification can dramatically alter surface chemical (catalytic) properties of the bimetallic system. ${ }^{1,13-19}$ Strong electronic perturbation between the metal overlayer and the underlying transition metal were observed in

Current address: Department of Physical Chemistry, Nuclear Research Center, Negev, P.O. Box 9001, Beer Sheva, Israel.
X-ray photoelectron spectroscopy (XPS) studies of $\mathrm{Cu} / \mathrm{Ru}(001)^{16}$ as in other bimetallic systems. ${ }^{15 a}$

By use of scanning tunneling spectroscopy (STM), the modified electronic structure was found to induce perturbations, which extend up to 50-100 $\AA$ away. They are observed at the step edges or adatoms that may alter adsorbate binding energy and generate new adsorption sites. ${ }^{20,21}$ Step edges of copper islands on $\mathrm{Ru}(001)$ were found to trap $\mathrm{H}$ and $\mathrm{CO}$ and thus reduce the diffusion coefficient of hydrogen on $\mathrm{Ru}(001)$ by 3 orders of magnitude by depositing only $0.2 \mathrm{ML}$ copper. ${ }^{22}$ These new adsorption sites are characterized by a substantially different local work function, probed by photoemission of adsorbed xenon (PAX). ${ }^{17-19}$

$\mathrm{Cu}$ is immiscible in $\mathrm{Ru}$, which circumvents the complication of determining the three-dimensional composition. It is known also to grow epitaxially on the clean $\mathrm{Ru}(001)$, forming a pseudomorphic film in the first layer. ${ }^{7-9}$ The pseudomorphic growth implies that the $\mathrm{Cu}-\mathrm{Cu}$ bond distances are strained $5.5 \%$ beyond the equilibrium distances found for bulk copper. The second layer is contracted practically to the interatomic distance of $\mathrm{Cu}(111)$ in one direction, while in the perpendicular direction the $\mathrm{Cu}$ atoms are still in registry with the $\mathrm{Ru}(001)$ atoms. The growth mechanism up to $4 \mathrm{ML}$ of $\mathrm{Cu}$ is "layer by layer". The well-characterized surface of the $\mathrm{Cu} / \mathrm{Ru}(001)$ system $^{7-9,23-25}$ makes it an ideal model bimetallic catalyst.

Although adsorption and desorption kinetics of several adsorbates have been studied on the $\mathrm{Cu} / \mathrm{Ru}(001)$ system, ${ }^{10-12}$ very few investigations have examined the dependence of the adsorption and dissociation mechanism on the copper coverage. Considerable insight into the catalytic processes can be gained by these investigations, although some discrepancy is found 
between the "real" polycrystalline $\mathrm{Cu} / \mathrm{Ru}$ catalyst powder and the smooth $\mathrm{Ru}(001)$ deposited by copper atoms. ${ }^{17}$ For example, in the $\mathrm{C}_{2} \mathrm{H}_{4} / \mathrm{Cu} / \mathrm{Ru}(001)$ system ${ }^{26}$ the copper deposition generated new adsorption sites that have mixed $\mathrm{Cu}$ and $\mathrm{Ru}$ character. The influence of these new sites on the dehydrogenation pathways of ethylene is a key issue for understanding the carbide layer formation, which is the final stage of the dehydrogenation sequence.

Recently, there had been considerable interest in the adsorption of methyl halides on single-crystal surfaces. ${ }^{27}$ The importance of these molecules as a model for surface alkylation and in particular their damaging role in atmospheric reactions motivated these studies. Under ultrahigh vacuum (UHV) conditions the reactivity toward $\mathrm{C}-\mathrm{X}$ bond cleavage follows the trend $\mathrm{I}>\mathrm{Br}>\mathrm{Cl}$ on several catalytic metal surfaces. Studies of $\mathrm{Ru}(001)$ indicate that $\mathrm{CH}_{3} \mathrm{I}$ dissociates completely upon adsorption at $100 \mathrm{~K} .{ }^{28} \mathrm{CH}_{3} \mathrm{Br}$ starts to only partially (55\%) dissociate at $125 \mathrm{~K},{ }^{29}$ and $\mathrm{CH}_{3} \mathrm{Cl}$ does not dissociate at all. ${ }^{30} \mathrm{On} \mathrm{Cu}(111)$ $\mathrm{CH}_{3} \mathrm{I}$ starts to partially dissociate at $140 \mathrm{~K},{ }^{31}$ but $\mathrm{CH}_{3} \mathrm{Br}$ does not. $^{32,33}$

From the three methyl halides the most interesting one in terms of its catalytic properties is $\mathrm{CH}_{3} \mathrm{Br}$ because of its rather different reactivity on copper and ruthenium. In the present study the interaction of the methyl bromide with the bare $\mathrm{Ru}(001)$ surface is compared to the $\mathrm{Cu}(0-2 \mathrm{ML}) / \mathrm{Ru}(001)$ surface in terms of characteristic adsorption sites and reactivity. The chemistry of the methyl fragment is thus used as a probe of the gradually changing nature of the metallic surface as the copper coverage increases. This reactive probe provides a complementary and a rather different viewpoint of the surface compared to the standard use of $\mathrm{CO}$ as a sensor. ${ }^{15 \mathrm{a}}$

\section{Experimental Section}

The experiments described here were performed in a UHV chamber with a base pressure of $3 \times 10^{-10}$ Torr obtained by a turbomolecular pump $(240 \mathrm{~L} / \mathrm{s})$. A sputter gun $\left(\mathrm{Ar}^{+}\right.$ions at 600 $\mathrm{V}$ and sample current of $8 \mu \mathrm{A})$ to clean the $\mathrm{Ru}(001)$ surface and a quadrupole mass spectrometer (QMS VG MASSTORR $\mathrm{DX}$ ) for $\Delta p$ TPD spectra were used. The QMS was surrounded by a Pyrex shroud with a $5 \mathrm{~mm}$ diameter aperture to minimize detection of desorbing molecules from surfaces other than the sample. A kelvin probe (Besocke type $S$ ) was employed to monitor the work function change $(\Delta \varphi)$. Both TPD and work function changes were measured as a function of crystal temperature using the same routine. A computer-controlled ac resistive heating method could, at the same time, control the heating rate or stabilization temperature $( \pm 0.5 \mathrm{~K})$ and collect data via an A/D converter either from the quadrupole to obtain $\Delta p$-TPD or from the kelvin probe controller to obtain $\Delta \varphi \mathrm{TPD}$ spectra.

The $\mathrm{Ru}(001)$ sample (a square piece, $8 \mathrm{~mm} \times 8 \mathrm{~mm}, 1.5$ $\mathrm{mm}$ thick) was cut from a single-crystal rod to within $\pm 1^{\circ}$ of the (001) crystallographic orientation and then polished by diamond paste having particles of $0.25 \mu \mathrm{m}$. Sample cleaning in UHV was described elsewhere. ${ }^{29}$ LEED from the clean and annealed surface showed a very sharp hexagonal pattern. The sample was attached to a liquid nitrogen reservoir via copper feedthroughs directly welded to the bottom of the Dewar. The ac resistive heating of two $0.5 \mathrm{~mm}$ diameter tantalum wires, between which the sample is spot-welded, was employed to control the sample temperature. (W5\% Re)-(W26\% Re) thermocouple wires spot-welded to the edge of the ruthenium sample were used for sample temperature determination and control.

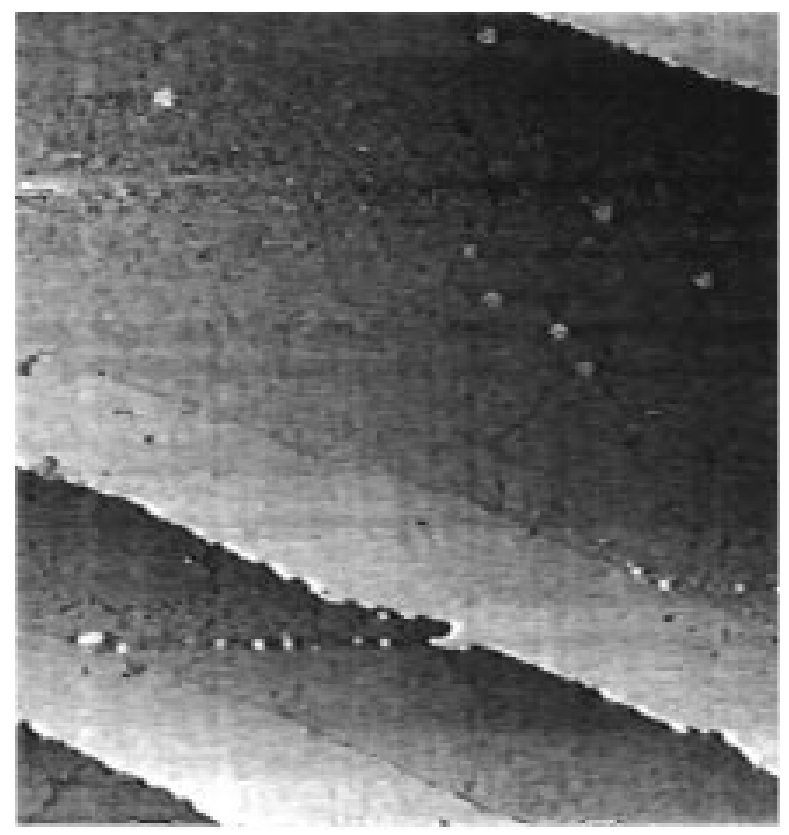

Figure 1. STM image of $0.3 \mathrm{ML}$ of $\mathrm{Cu}$ deposited on $\mathrm{Ru}(001)$ at 650 $\mathrm{K}$, recorded by Ammer and co-workers. ${ }^{9 \mathrm{a}}$ Image conditions are 190 $\mathrm{nm} \times 200 \mathrm{~nm}, 1 \mathrm{nA}$, and $-60 \mathrm{mV}$ bias voltage. The darker areas are of the $\mathrm{Ru}(001)$ substrate, and the bright stripes are of the copper terraces.

$\mathrm{CH}_{3} \mathrm{Br}(99.5 \%$ pure) was further purified by a few freezepump - thaw cycles to eliminate any noncondensable residual gases. Exposure was done by filling the chamber through a leak valve to the desired pressure, with the uncorrected ion gauge signal transmitted to a computer and converted to Langmuir units $\left(1 \mathrm{~L}=10^{-6}\right.$ Torr s).

Copper was evaporated onto the $\mathrm{Ru}(001)$ sample from a resistively heated Ta wire wrapped in high-purity $\mathrm{Cu}$ wire $(99.999 \%)$. The Ta filament was covered by a Pyrex shroud with a $5 \mathrm{~mm}$ diameter aperture. The $\mathrm{Cu}$ source was thoroughly degassed prior to deposition and was controlled by monitoring the voltage drop across the Ta wire at constant current. The copper coverage was determined by TPD after each experiment. The pressure rise during copper evaporation was routinely (1$2) \times 10^{-10}$ Torr. The sample was held during evaporation at $640 \mathrm{~K}$ in order to avoid CO adsorption and to produce a wellannealed surface, thus avoiding three-dimensional clustering of copper on the $\mathrm{Ru}(001)$ surface..$^{7,9}$

\section{Results and Discussions}

1. $\mathbf{C u} / \mathbf{R u}(\mathbf{0 0 1})$. Deposition of copper on $\mathrm{Ru}(001)$ has been extensively studied by STM ${ }^{7-9}$ and by other methods. ${ }^{23-25} \mathrm{Up}$ to a coverage of at least four monolayers (ML), the observed growth behavior is compatible with both layer-by-layer and layer/3D-cluster growth modes, strongly dependent on crystal temperature and deposited atom flux. At a surface temperature of $300 \mathrm{~K}$, second-layer islands are formed already around $\theta_{\mathrm{Cu}}$ $=0.8 \mathrm{ML}$, and at coverages higher than 1.2 ML third-layer islands are also observed. Annealing to $520 \mathrm{~K}$ was found to dissolve the third layer into the first two layers. In conclusion, when adsorption temperature is above $500 \mathrm{~K}$, the growth mode at submonolayer levels is always by a step flow mechanism. ${ }^{7-9}$

In Figure 1 an STM image is presented of $0.3 \mathrm{ML} \mathrm{Cu} / \mathrm{Ru}(001)$ deposited at $650 \mathrm{~K}$, as taken by Ammer et al..$^{9 \mathrm{a}}$ The deposited copper atoms (bright stripes) are mobile enough to be captured by the $\mathrm{Ru}(001)$ step edges. Further $\mathrm{Cu}$ deposition results in a step flowlike growth mode, which is supposed to wet the 
a
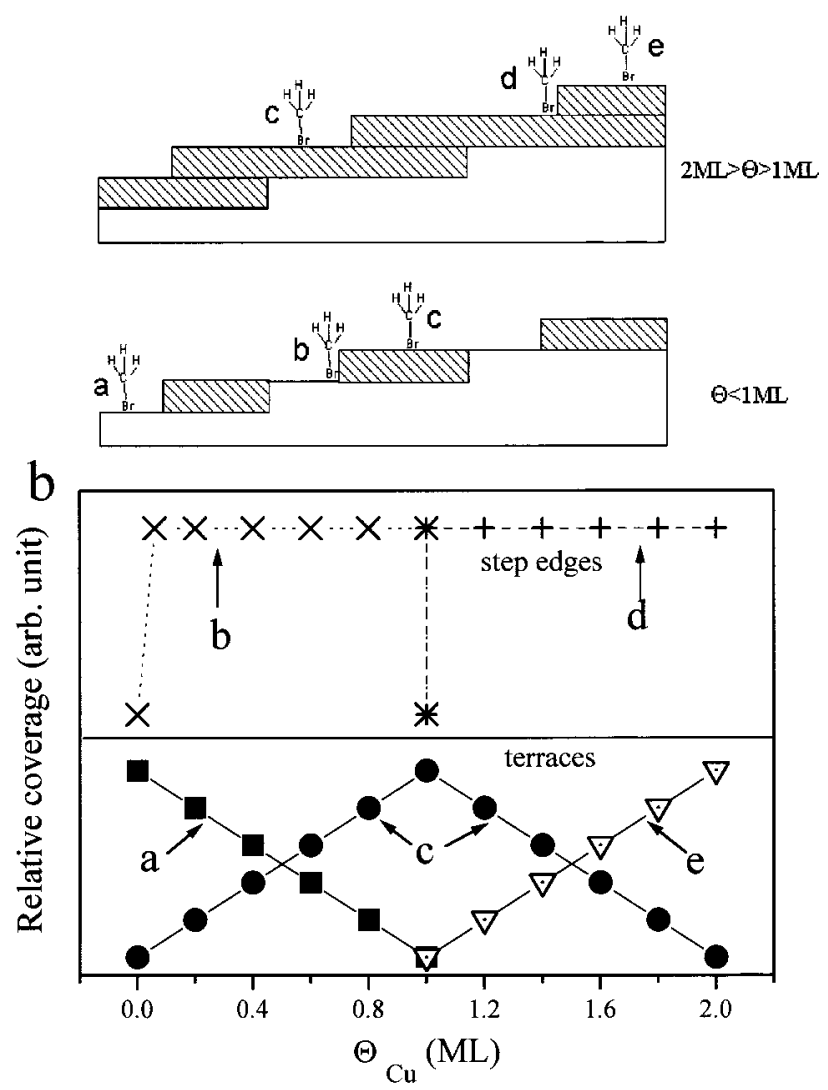

Figure 2. (a) Scheme of the $\mathrm{Cu} / \mathrm{Ru}(001)$ surface representing the typical sites for a $\mathrm{CH}_{3} \mathrm{Br}$ molecule when adsorbed on $\mathrm{Cu}(0-2 \mathrm{ML}) /$ $\mathrm{Ru}(001)$. The copper was deposited at a crystal temperature of $640 \mathrm{~K}$. The copper coverage regimes are indicated as follows: (a) $\mathrm{Ru}(001)$ surface, (b) $\mathrm{Cu}(1 \mathrm{ML}) / \mathrm{Ru}(001)$ step edges, (c) $\mathrm{Cu}(1 \mathrm{ML}) / \mathrm{Ru}(001)$ terraces, (d) $\mathrm{Cu}(2 \mathrm{ML}) / \mathrm{Ru}(001)$ step edges, (e) $\mathrm{Cu}(2 \mathrm{ML}) / \mathrm{Ru}(001)$ terraces. (b) Distribution of $\mathrm{a}-\mathrm{e}$ sites as a function of copper coverage.

substrate surface completely at $1 \mathrm{ML}$ of $\mathrm{Cu}$. The step flow regime is preserved up to 3-4 $\mathrm{ML}$ of $\mathrm{Cu}$ even if individual $\mathrm{Cu}$ islands do exist on the surface. However, despite the layer-bylayer growth, small bare $\mathrm{Ru}$ patches were still observed under experimental conditions similar to those of the present work, up to at least 1.4 ML, believed to be generated around defect sites. ${ }^{26}$ Furthermore, even high annealing temperatures could not completely eliminate these rather stable vacancies within the first copper layer on the $\mathrm{Ru}(001)$ surface. ${ }^{8 b}$

On the basis of the growth scheme depicted from the STM study described above in Figure 1, we have marked specific adsorption sites of the $\mathrm{CH}_{3} \mathrm{Br}$ molecules on the gradually coppercovered $\mathrm{Ru}(001)$ surface. The various sites are classified into five groups, sketched in Figure 2a, as a function of copper coverage: (a) clean $\mathrm{Ru}(001)$ terraces, (b) $\mathrm{Cu}(1 \mathrm{ML}) / \mathrm{Ru}(001)$ step edges, (c) $\mathrm{Cu}(1 \mathrm{ML}) / \mathrm{Ru}(001)$ terraces, (d) $\mathrm{Cu}(2 \mathrm{ML}) /$ $\mathrm{Ru}(001)$ step edges, and (e) $\mathrm{Cu}(2 \mathrm{ML}) / \mathrm{Ru}(001)$ terraces. The differences in the morphology of the surface observed as the copper coverage increases above $2 \mathrm{ML}^{7-9}$ are not reflected in the parent molecule's $\Delta p$ TPD spectra, which remains unchanged. Therefore, the e sites are taken to represent the $\mathrm{Cu}(>2$ $\mathrm{ML}) / \mathrm{Ru}(001)$ as well. The density of the various types of sites as a function of copper coverage is shown in Figure 2b. The model described in this figure is valid under the assumption that the step edge concentration is constant. However, we note that the terraces are not necessarily equally spaced, which might result in sites of type $d$ at copper coverages less than $1 \mathrm{ML}$.

Temperature-programmed desorption spectra of copper from $\mathrm{Ru}(001)$ are well documented in the literature ${ }^{23,25 a}$ and clearly separate the first from the second layers. We have used the integrated TPD of copper in order to determine the copper coverages at an accuracy of 5\%. The work function change of the $\mathrm{Ru}(001)$ surface as a function of copper coverage, calibrated against the integrated area under the corresponding $\Delta p$ TPD peak, has been measured (not shown). This is in order to evaluate the work function contribution by the methyl bromide on the copper-covered surface. The work function decreases monotonically down to $-0.72 \mathrm{eV}$ at $1 \mathrm{ML}$ of copper, and then it is kept fixed up to $2 \mathrm{ML}$ and above. These numbers agree very well with the continuous work function change measurements taken during copper deposition on the same surface and reported previously. ${ }^{25 a}$

This observation demonstrates that the work function of a metallic overlayer does not necessarily correlate with the chemical reactivity on this layer. As will be demonstrated below, the unique chemistry of methyl fragments on $\mathrm{Cu}(1 \mathrm{ML}) /$ $\mathrm{Ru}(001)$, which is rather different from the chemistry on $\mathrm{Cu}(111)$, has been recorded.

2. $\mathrm{CH}_{3} \mathrm{Br}$ on $\mathrm{Cu}(2 \mathrm{ML}) / \mathrm{Ru}(001)$. Characterization of the adsorption state of methyl bromide was obtained by a combination of work function change measurements during adsorption at $82 \mathrm{~K}$ followed by $\Delta p$ TPD at the molecular mass of $\mathrm{CH}_{3} \mathrm{Br}$ $(m / e=94)$. These studies indicate that the molecule does not dissociate upon adsorption at this temperature on the clean $\mathrm{Ru}(001) .{ }^{29}$ We have used these techniques to study and compare the effect of $2 \mathrm{ML}$ of copper on the same surface in terms of the molecular behavior.

Work function change measurements during adsorption of methyl bromide on the $\mathrm{Cu}(2 \mathrm{ML}) / \mathrm{Ru}(001)$ surface reveal behavior very similar to that previously reported on the clean $\mathrm{Ru}(001)^{29}$ and are shown in Figure 3. The first monolayer induces a decrease of $1.33 \mathrm{eV} \pm 0.05$ (compared with $2.15 \mathrm{eV}$ \pm 0.02 on the clean $\mathrm{Ru}(001)$ ), while the second layer causes a smaller increase, again similar but at a smaller magnitude compared with the clean ruthenium. This behavior has been interpreted in terms of a molecular adsorption geometry where the first-layer molecules adsorb with the bromine facing the metal surface while in the second layer it is predominantly adsorbed in the opposite geometry. ${ }^{29}$ The overall smaller magnitude of the work function change that was found on the copper-covered surface suggests that the adsorption geometry on this surface is characterized by a higher level of disorder. Probably a significant fraction of the molecules are tilted with respect to the surface normal, in agreement with reports on the geometry of this molecule on $\mathrm{Cu}(111)^{32}$ and $\mathrm{Cu}(10 \mathrm{ML})$ / $\mathrm{Ru}(001) .{ }^{39}$

It is interesting to note that the alternating adsorption geometry within the first layers of methyl bromide on the clean $\mathrm{Ru}(001)$, inferred from the work function change data, is consistent with the molecular crystal structure. ${ }^{34}$ The behavior on the copper-covered surface suggests that the interaction of methyl bromide with copper induces geometrical changes within the first layer, which prevent the growth of well-ordered bulklike crystal.

Once the methyl bromide molecules adsorb on the $2 \mathrm{ML}$ copper-covered ruthenium surface, $\Delta p$ TPD measurements at the molecular mass were performed. In Figure 4, a comparison is made between the spectra obtained from the clean $\mathrm{Ru}(001)$ and those from the $\mathrm{Cu}(2 \mathrm{ML}) / \mathrm{Ru}(001)$ surface. These spectra 


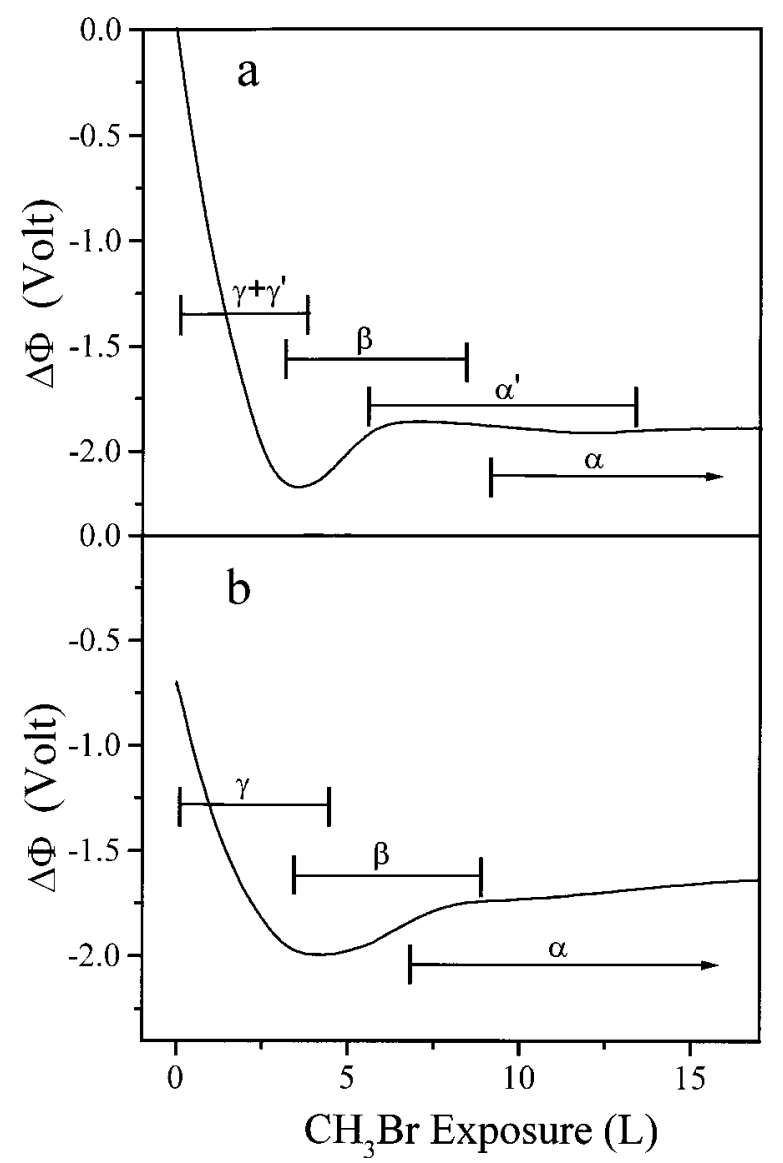

Figure 3. Work function change measurement during $\mathrm{CH}_{3} \mathrm{Br}$ adsorption at $82 \mathrm{~K}$ on (a) $\mathrm{Ru}(001)$ and (b) $\mathrm{Cu}(2 \mathrm{ML}) / \mathrm{Ru}(001)$. The onset and completion of each desorption peak (shown in Figure 4) are indicated.

serve as indicators of the strength of interaction of the molecule with the underlying metallic surface. It is clearly seen that the ruthenium is highly reactive upon sample heating, dissociating 0.55 of the initial $1 \mathrm{ML}$ of adsorbed methyl bromide. In contrast, the $\mathrm{Cu}(2 \mathrm{ML}) / \mathrm{Ru}(001)$ surface is quite inert, leading to the dissociation of only 0.06 of the initial $1 \mathrm{ML}$ of $\mathrm{CH}_{3} \mathrm{Br}$ (note the similar ordinate's scale in both insets), which is probably due to defects in the copper layer. Theses defects are stable even after annealing to temperatures around $1000 \mathrm{~K}^{7-9}$

The $\gamma$ molecular desorption peak (Figure 4), attributed to the first $\mathrm{CH}_{3} \mathrm{Br}$ layer on the $\mathrm{Cu}(2 \mathrm{ML}) / \mathrm{Ru}(001)$ surface, shifts from $170 \mathrm{~K}$ at low coverages to $150 \mathrm{~K}$ at $1 \mathrm{ML}$ because of dipoledipole repulsion. ${ }^{29,30,35} \mathrm{In}$ addition to the minor methyl bromide dissociation, $2 \mathrm{ML}$ of copper reduces substantially the binding energy of the isolated $\mathrm{CH}_{3} \mathrm{Br}$ molecule to the surface, as seen from the lower desorption temperature at low coverages. By use of a preexponential factor of $3 \times 10^{13} \mathrm{~s}^{-1}$, the low-coverage (isolated molecule) activation energy for desorption from the copper-covered surface is $42 \mathrm{~kJ} / \mathrm{mol}$, as obtained from a full desorption line shape analysis.

Calibration of the total molecular desorption uptake obtained from the clean $\mathrm{Ru}(001)^{29}$ to that from $\mathrm{Cu}(2 \mathrm{ML}) / \mathrm{Ru}(001)$ enabled the semiquantitative definition of the $\mathrm{CH}_{3} \mathrm{Br}$ density on that surface at the completion of a monolayer. Considering the somewhat higher density of copper atoms on $\mathrm{Cu}(111)$, by a factor of 1.114 compared with that of ruthenium atoms on $\mathrm{Ru}(001)$, we came up with a density of $1 \mathrm{ML}$ of methyl bromide of $\mathrm{CH}_{3} \mathrm{Br} / \mathrm{Cu}=0.22 \pm 0.02$ (identical to the packing on the clean $\mathrm{Ru}(001))$, which translates to $(4.0 \pm 0.3) \times 10^{14}$ molecules $/ \mathrm{cm}^{2}$.

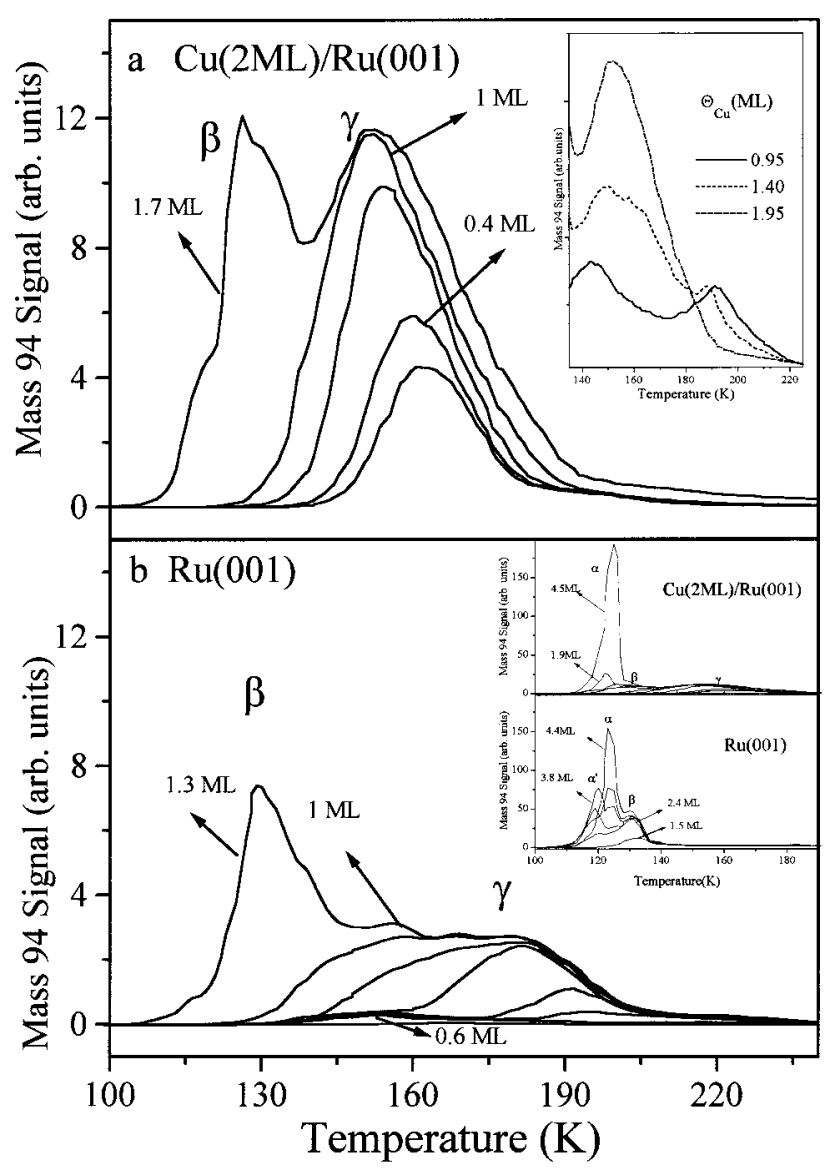

Figure 4. $\Delta p$ TPD spectra of $\mathrm{CH}_{3} \mathrm{Br}(m / e=94)$ at the indicated molecular coverages from (a) $\mathrm{Cu}(2 \mathrm{ML}) / \mathrm{Ru}(001), 0.3-1.7 \mathrm{ML}$ of $\mathrm{CH}_{3} \mathrm{Br}$. The inset shows $\Delta p$ TPD for the indicated $\mathrm{Cu} / \mathrm{Ru}(001)$ coverages and subsequent exposure to $6 \mathrm{~L}$ of $\mathrm{CH}_{3} \mathrm{Br}$. (b) Clean $\mathrm{Ru}(001), 0.1-1.3 \mathrm{ML}$ of $\mathrm{CH}_{3} \mathrm{Br}$. The inset shows the indicated desorption spectra obtained from the multilayer methyl bromide coverage regime for $\mathrm{Cu}(2 \mathrm{ML}) / \mathrm{Ru}(001)$ and the clean $\mathrm{Ru}(001)$. Adsorption temperature was $82 \mathrm{~K}$ and the heating rate $3 \mathrm{~K} / \mathrm{s}$.

This density can then be used to estimate the low coverage (isolated molecule) dipole moment of adsorbed methyl bromide $(\mu(0))$. We obtained a dipole moment estimate $\mu(0)=1.55 \mathrm{D}$ from the initial slope of work function vs coverage plot in Figure 3. This dipole moment is smaller than the gas-phase value of $1.82 \mathrm{D},{ }^{40}$ in contrast to typical cases where an adsorbed molecular state is more polarized because of the formation of surface bonding, which often results in a large dipole moment. This can be explained only on the basis of adsorption geometry arguments, which favor a significant degree of tilt of the adsorbed molecule on the $\mathrm{Cu}(2 \mathrm{ML}) / \mathrm{Ru}(001)$ surface.

Finally, in the inset of Figure $4 \mathrm{~b}$, the desorption spectra obtained from the multilayer methyl bromide coverage regime are shown. The $\beta$ peak is centered at $130 \mathrm{~K}$ and is attributed to second-layer desorption. The $\alpha$ peak for the $2 \mathrm{ML} \mathrm{Cu} / \mathrm{Ru}(001)$ surface is attributed to the condensed phase, and similar to the clean $\mathrm{Ru}(001)$, it peaks around $126 \mathrm{~K}$. The sensitivity of the desorption spectra to the underlying substrate is evident. Although on the clean $\mathrm{Ru}(001)$ unique low-temperature desorption from a third layer ( $\alpha^{\prime}$ peak) was observed, it is absent in the desorption from the $\mathrm{Cu}(2 \mathrm{ML}) / \mathrm{Ru}(001)$ surface.

Destabilization of the third layer and then a more stable fourth and thicker layers on the clean $\mathrm{Ru}(001)$ has been discussed in terms of bulklike molecular crystalline structure formation. ${ }^{29,30}$ It turns out that on the copper-covered surface destabilization of the third layer is not observed. On the basis of the work function change spectrum during adsorption, we conclude that 
on the $\mathrm{Cu}(2 \mathrm{ML}) / \mathrm{Ru}(001)$ surface, $\mathrm{CH}_{3} \mathrm{Br}$ molecules cannot form a structure according to the molecular crystalline antiparallel arrangement ${ }^{34}$ as well as on the clean $\mathrm{Ru}(001)$ surface. This may be related to the fact that on this surface there are more defects, and as a result, molecules adsorb in a distribution of tilt angles with respect to the normal to the surface.

3. $\mathbf{C u}(\mathbf{0}-\mathbf{2 M L}) / \mathbf{R u}(\mathbf{0 0 1})$. 3.1. $\mathrm{CH}_{3} \mathrm{Br}$ Desorption. The desorption of methyl bromide from the $\mathrm{Cu} / \mathrm{Ru}(001)$ surface is expected to reflect the distribution of sites shown in Figure 2. The $\Delta p$ TPD spectra of $\mathrm{CH}_{3} \mathrm{Br}$ at the monolayer coverage regime for three copper coverages between $\theta_{\mathrm{Cu}}=0.95$ and $\theta_{\mathrm{Cu}}$ $=1.95$ are shown in the inset of Figure $4 \mathrm{a}$. These spectra demonstrate the effect of copper sites on the molecular desorption. Two desorption peaks at 145 and $195 \mathrm{~K}$ are assigned to desorption from first-layer copper terraces (c) and copper step edges (b, d) sites, respectively. Exact assignment of each of the desorption peaks to a given site is probably impossible. These small desorption peaks change with copper coverage, and above 2 ML they coalesce into a single $155 \mathrm{~K}$ desorption peak, which is believed to correlate with site e in Figure 2. The activation energy from this site is $47 \mathrm{~kJ} / \mathrm{mol}$, assuming the same $\left(3 \times 10^{13} \mathrm{~s}^{-1}\right)$ preexponential factor as above. This indicates that the binding energy at the step $\mathrm{Cu} / \mathrm{Ru}$ edges is $5 \mathrm{~kJ} / \mathrm{mol}$ higher than the binding on the $\mathrm{Cu}(2 \mathrm{ML}) / \mathrm{Ru}(001)$ terraces.

Correlation of the work function change data obtained during desorption $(\Delta \varphi$ TPD) with $\Delta p$ TPD provides important and often unique information on the dependence of the dissociation mechanism of adsorbed methyl on copper coverage. The $\Delta \varphi$ TPD after exposure of $\mathrm{Cu}(0-2 \mathrm{ML}) / \mathrm{Ru}(001)$ surfaces to $6 \mathrm{~L}$ of methyl bromide at $82 \mathrm{~K}$ is shown in Figure 5. All changes in the work function refer to the clean $\mathrm{Ru}(001)$ surface and include contributions to $\Delta \varphi$ due to both copper and the methyl bromide. For $\theta_{\mathrm{Cu}}<0.8 \mathrm{ML}$ (dashed-dotted lines) the main influence of the copper is observed between 200 and $400 \mathrm{~K}$. At this temperature range the adsorbed methyl dehydrogenates almost completely to $\mathrm{CH}$ fragments on the clean $\mathrm{Ru}(001)$ surface. ${ }^{28,29}$ The very different $\Delta \varphi$ TPD spectra caused by copper at coverages as low as $0.11 \mathrm{ML}$ (not shown) indicate that the methyl dehydrogenation reaction is very sensitive to the electron density changes exerted by the adsorbed copper. The different reactivity pattern on the copper-covered, compared with the clean $\mathrm{Ru}(001)$ surface, is attributed to the copper step edges and their surroundings, where the dehydrogenation reaction rate of the $\mathrm{CH}_{2}$ fragments is faster (see section 3.3 below). This statement is supported by previous reports on the special role step edges of copper on ruthenium have in, for example, slowing the diffusion of $\mathrm{H}$ and $\mathrm{CO}$ on this surface. ${ }^{22}$

At $\theta_{\mathrm{Cu}} \geq 0.8 \mathrm{ML}$ (solid lines), an abrupt change is observed in the $\Delta \varphi$ TPD spectra. A $\Delta \varphi$ decrease around $300 \mathrm{~K}$ disappears, and a $\Delta \varphi$ rise around $400 \mathrm{~K}$ emerges. These results correspond to similar changes observed in the $\Delta p$ TPD spectra, which mark the modification in the dehydrogenation pathway of the adsorbed methyl, as will be discussed in the next section.

Following the decomposition of parent $\mathrm{CH}_{3} \mathrm{Br}$ and its methyl fragment using work function change measurements requires special care. This is due to the opposing effects generated by the gradual increase of the copper coverage: decreasing reactivity toward the parent molecule and its decomposition fragments but at the same time opposite $\Delta \varphi$ change due to bromine atoms left on the $\mathrm{Cu}$ vs $\mathrm{Ru}$ surface.

In the inset of Figure 5, the change in $\Delta \varphi$ attributed to the adsorbed fragments (carbon and bromine) left on the surface after a $\Delta \varphi$ TPD run up to $550 \mathrm{~K}$ is shown. This is measured by subtracting the initial reading at $82 \mathrm{~K}$, prior to the adsorption

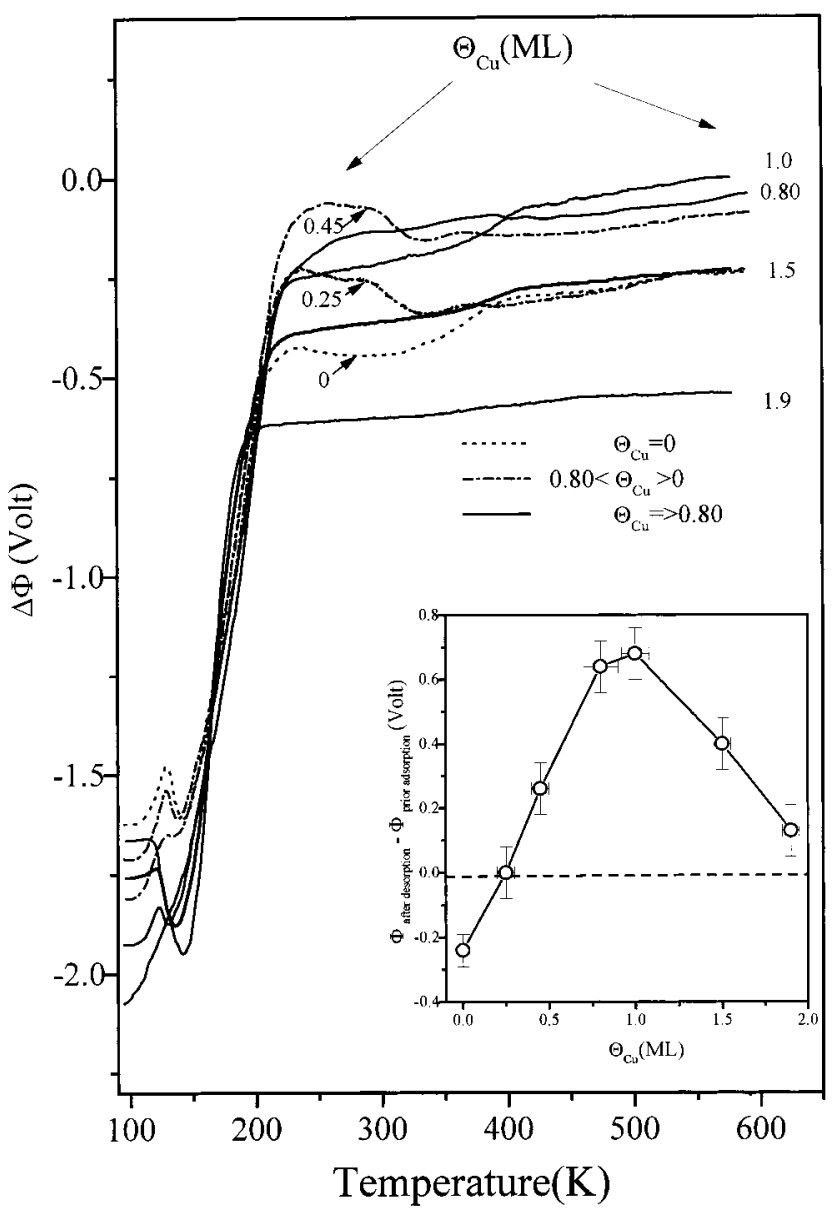

Figure 5. Work function change during temperature-programmed desorption $\left(\Delta \varphi\right.$ TPD) of $\mathrm{CH}_{3} \mathrm{Br}$ from $\mathrm{Cu}(0-1.9 \mathrm{ML}) / \mathrm{Ru}(001)$ at the indicated copper coverages. The initial $\Delta \varphi$ (at $82 \mathrm{~K}$ ) comprises the $\Delta \varphi$ due to adsorbed copper and subsequent exposure to $6 \mathrm{~L}$ of $\mathrm{CH}_{3} \mathrm{Br}$. In the inset, the difference between the measured $\Delta \varphi$ at $82 \mathrm{~K}$ before exposing the surface to $6 \mathrm{~L}$ of $\mathrm{CH}_{3} \mathrm{Br}$ and the one obtained at $550 \mathrm{~K}$ following $\Delta \varphi$ TPD runs is shown. The heating rate was $2 \mathrm{~K} / \mathrm{s}$.

of $6 \mathrm{~L}$ of $\mathrm{CH}_{3} \mathrm{Br}$ on the $\mathrm{Cu} / \mathrm{Ru}(001)$ surface, from the $\Delta \varphi$ value detected after sample heating to $550 \mathrm{~K}$. Bromine forms a $(\sqrt{ } 3$ $\times \sqrt{ } 3) \mathrm{R} 30^{\circ}$ structure on $\mathrm{Cu}(111) .{ }^{41} \mathrm{We}$ assume that a similar structure is formed on both $\mathrm{Ru}(001)$ and $\mathrm{Cu}(2 \mathrm{ML}) / \mathrm{Ru}(001)$, defining this as $1 \mathrm{ML}$ of bromine coverage (namely, $1 \mathrm{ML}=$ $\mathrm{Br} / \mathrm{Ru}=0.33$ ). This assumption is based on the expected similarity with the identical ordered structure formed by chlorine on $\mathrm{Cu}(111)^{42}$ and on $\mathrm{Ru}(001) .{ }^{43}$ At $1 \mathrm{ML}$ of coverage the work function change induced by bromine atoms is +0.8 and -0.32 $\mathrm{V}$ on $\mathrm{Cu}(111)^{41}$ and $\mathrm{Ru}(001),{ }^{29}$ respectively.

The fraction of dissociated $\mathrm{CH}_{3} \mathrm{Br}$ gradually decreases upon increasing copper coverage. It diminishes from 0.55 of a saturated monolayer-adsorbed methyl bromide on the clean $\mathrm{Ru}(001)$ to 0.06 of the initial monolayer on the $\mathrm{Cu}(2 \mathrm{ML}) /$ $\mathrm{Ru}(001)$ surface. This accounts for the amount of bromine adsorbed on the surface. The reactivity difference toward dehydrogenation of methyl groups between $\mathrm{Ru}$ and $\mathrm{Cu}$ is reflected by the decreasing amount of carbon deposited on the surface as the copper coverage increases. $\Delta \varphi$ measurements following $\mathrm{C}_{2} \mathrm{H}_{4}$ decomposition have indicated that carbide atoms contribute $+0.2 \mathrm{~V}$ for an estimated carbon coverage of $\mathrm{C} / \mathrm{Ru}(001)$ of 0.11 .44

Bromine atoms left on the surface as a result of the decomposition of methyl bromide lead to a $\Delta \varphi$ increase as the copper coverage grows. The work function change attributed to the adsorbed hydrocarbon fragments at $550 \mathrm{~K}$ reverses its 
sign at $\theta_{\mathrm{Cu}}>0.30 \mathrm{ML}$, and around $\theta_{\mathrm{Cu}}=1 \mathrm{ML}$, the work function change is maximized at $0.68 \mathrm{~V}$. The turnover and decrease of $\Delta \varphi$ at $\theta_{\mathrm{Cu}}>1 \mathrm{ML}$ is attributed to the gradual passivation of the surface by copper, which suppresses the molecular dissociation, resulting in a lower bromine coverage.

There is an interplay between the decreasing dissociation probability as the copper coverage increases, and the increasing work function change, due to each bromine atom that binds to copper and not to ruthenium. While on the clean $\mathrm{Ru}(001)$ surface the contribution of bromine atoms is negative, ${ }^{29}$ as we increase the copper coverage to $1 \mathrm{ML}$, more bromine atoms adsorb on copper terraces and their step edges and contribute positively to the work function. Even at low copper coverages, where the molecules most likely dissociate on clean ruthenium sites and not at step edges of copper, the bromine atoms find their way to the nearest copper step edges, inducing positive change in $\Delta \varphi$.

In general, $\Delta \varphi$ TPD spectra reproduce rather accurately the behavior observed in the corresponding $\Delta p$ TPD. One can further emphasize the similarity between these complementary methods by differentiating the $\Delta \varphi$ TPD spectra with respect to temperature, as was discussed in ref 29 , and this will be demonstrated below for the desorption of methane.

3.2. $\mathbf{C H}_{3}$ Chemistry on $\mathbf{C u} / \mathbf{R u}(001)$. 3.2.1. $\mathrm{CH}_{3} / \mathrm{Cu}(\mathrm{O}-$ $2 M L) / R u(001)$. Two different $\Delta p$ TPD signals at $m / e=16$ (dotted lines) and $m / e=2$ (solid lines) following the exposure of $\mathrm{Ru}(001)$ surfaces (covered by the indicated copper coverages $\theta_{\mathrm{Cu}}=0-1.95 \mathrm{ML}$ ) to $6 \mathrm{~L}$ of $\mathrm{CH}_{3} \mathrm{Br}$ at $82 \mathrm{~K}$ are shown in Figure 6. These signals reflect the catalytic production of $\mathrm{CH}_{4}$ and $\mathrm{H}_{2}$, respectively. The fraction of dissociated $\mathrm{CH}_{3} \mathrm{Br}$ ( sum of $\mathrm{H}_{2}$ and total $\mathrm{CH}_{4}$ uptake) as a function of copper coverage is summarized in Figure 7. The dissociation of $\mathrm{CH}_{3} \mathrm{Br}$ clearly decreases with increasing copper coverage, as determined by the hydrogen uptake, which gradually vanishes, and the total methane signal, which increases as $\theta_{\mathrm{Cu}}$ grows toward $1 \mathrm{ML}$. Around $\theta_{\mathrm{Cu}}=0.8$ ML, the hydrogen desorption peak develops a low-temperature tail while methane desorption at $195 \mathrm{~K}$ broadens toward higher temperatures. At $0.95>\theta_{\mathrm{Cu}}>0.8 \mathrm{ML}$, the hydrogen desorption disappears concomitantly with the emergence of a new desorption peak of methane centered on $370 \mathrm{~K}$ with a tail at $450 \mathrm{~K}$. This sudden change in the adsorbed methyl dissociation pathway above $250 \mathrm{~K}$ at a narrow copper coverage range is seen also in the $\Delta \varphi$ TPD spectra (Figure 5) and nicely demonstrates the kind of selectivity one would expect from a bimetallic catalyst.

Hydrogen atoms were shown to "spill over" from the ruthenium terraces on top of the copper-covered areas around $130 \mathrm{~K}^{45}$ Our data suggest that around $\theta_{\mathrm{Cu}}=0.8 \mathrm{ML}$, the adsorbed hydrogen density produced by the dissociation of the methyl species is higher than the capacity of the remaining clean $\mathrm{Ru}$ terraces. As a result, hydrogen "spills over" on top of the copper terraces, where it recombines with adsorbed methyl (which also reside on the copper following diffusion and "spill over" from the ruthenium sites) to produce methane. Up to $\theta_{\mathrm{Cu}}$ $=0.95 \mathrm{ML}$ a regime is maintained for which adsorbed hydrogen and methyl species coexist, resulting in an overlap of their $\Delta p$ TPD spectra between 230-280 K (Figure 6e). Further increase of the copper coverage above $0.95 \mathrm{ML}$ results in decreased methyl radical density due to diminishing parent molecule dissociation. In addition, the methyl dissociation also gradually slows down, and thus, the hydrogen coverage is reduced. The absence of any hydrogen desorption for $\theta_{\mathrm{Cu}}>0.95 \mathrm{ML}$ is understood in terms of the low hydrogen coverage, which makes the recombination reaction with methyl to form methane the dominating reactivity channel.

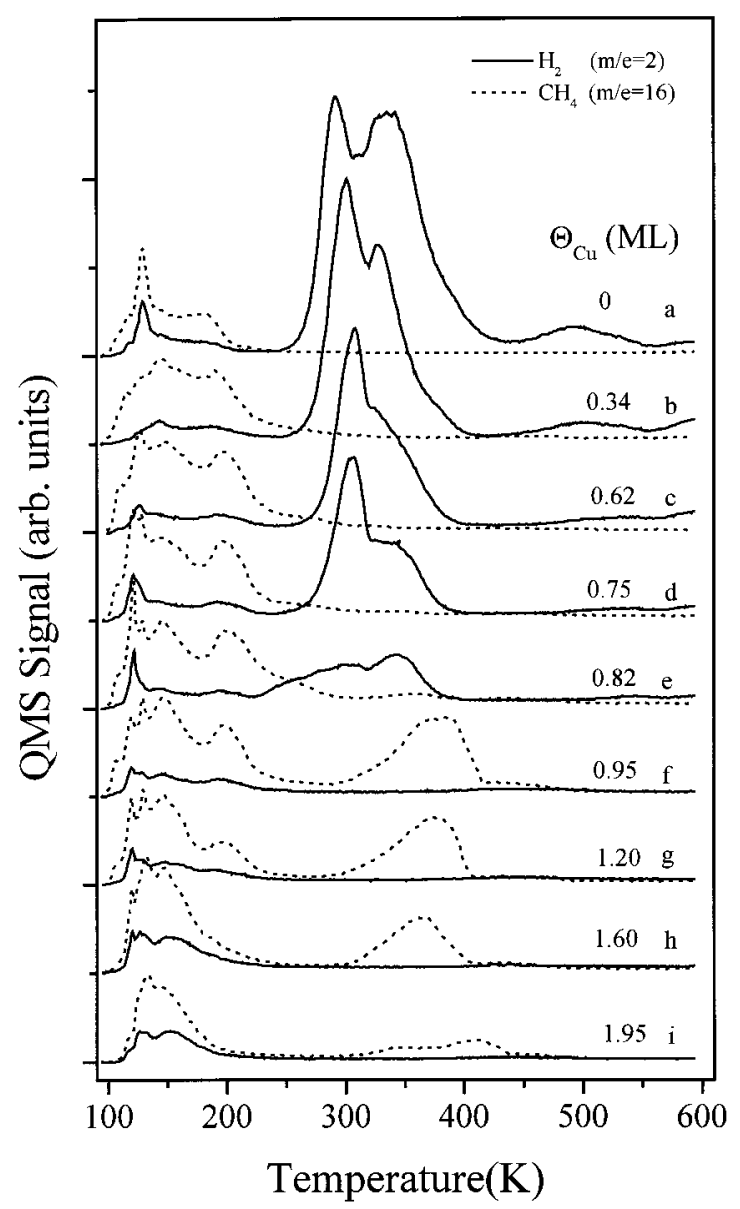

Figure 6. $\Delta p$ TPD spectra at $m / e=2\left(\mathrm{H}_{2}\right.$, solid lines $)$ and $m / e=16$ $\left(\mathrm{CH}_{4}\right.$, dotted lines) after exposing $\mathrm{Cu} / \mathrm{Ru}(001)$ surfaces at the indicated copper coverages $(0-1.95 \mathrm{ML})$ to $6 \mathrm{~L}$ of $\mathrm{CH}_{3} \mathrm{Br}$. Adsorption temperature was $82 \mathrm{~K}$ and the heating rate $3 \mathrm{~K} / \mathrm{s}$.

Around $200 \mathrm{~K}$ the methane desorption rate first increases as $\theta_{\mathrm{Cu}} \rightarrow 0.95 \mathrm{ML}$ and then it decreases again as the second copper layer starts to build up. For $\theta_{\mathrm{Cu}}>2 \mathrm{ML}$ methane production is practically eliminated. On the bare $\mathrm{Ru}$ surface, methyl dehydrogenation is faster around $200 \mathrm{~K}$ than the hydrogenation channel to form $\mathrm{CH}_{4} \cdot{ }^{29}$ It is believed, therefore, that the desorption of methane near $200 \mathrm{~K}$ originates from $\left(\mathrm{CH}_{3}\right)_{\mathrm{ad}}$ fragments at copper step edges or from those "spilled over" on top of the copper terraces. These $\left(\mathrm{CH}_{3}\right)_{\text {ad }}$ species then recombine with hydrogen atoms produced at the same temperature range from dehydrogenation of other $\left(\mathrm{CH}_{3}\right)_{\mathrm{ad}}$ on the bare $\mathrm{Ru}$ sites. We note that at submonolayer copper coverages, even if methyl resides on top of the copper layer, its diffusion is fast enough to reach free $\mathrm{Ru}(001)$ sites and may dehydrogenate. As discussed above, the abundance of $\mathrm{Ru}$ sites that enable $\left(\mathrm{CH}_{3}\right)_{\text {ad }}$ dissociation is reduced at $\theta_{\mathrm{Cu}}>0.8 \mathrm{ML}$ (as is expressed by the hydrogen and methyl species coexistence between 230-280 K) and diminishes at $\theta_{\mathrm{Cu}}>0.95 \mathrm{ML}$. Possibly, electronic structure modifications generated by the bimetallic system contribute to the reduced dehydrogenation reactivity on the $\mathrm{Ru}$ sites. As shown by STM measurements ${ }^{20,21}$ on other systems, step edges exert long-range electron density modifications on the surface $(50-100 \AA)$. If the range of these changes is similar to the average distance between the copper terraces, there will be no available $\mathrm{Ru}$ sites that are of pure $\mathrm{Ru}$ nature. Therefore, dehydrogenation of $\left(\mathrm{CH}_{3}\right)_{\mathrm{ad}}$ is expected to be significantly perturbed and eventually be totally blocked. This can be understood in terms of an "ensamble" effect in the surface reactivity of the methyl fragments. 


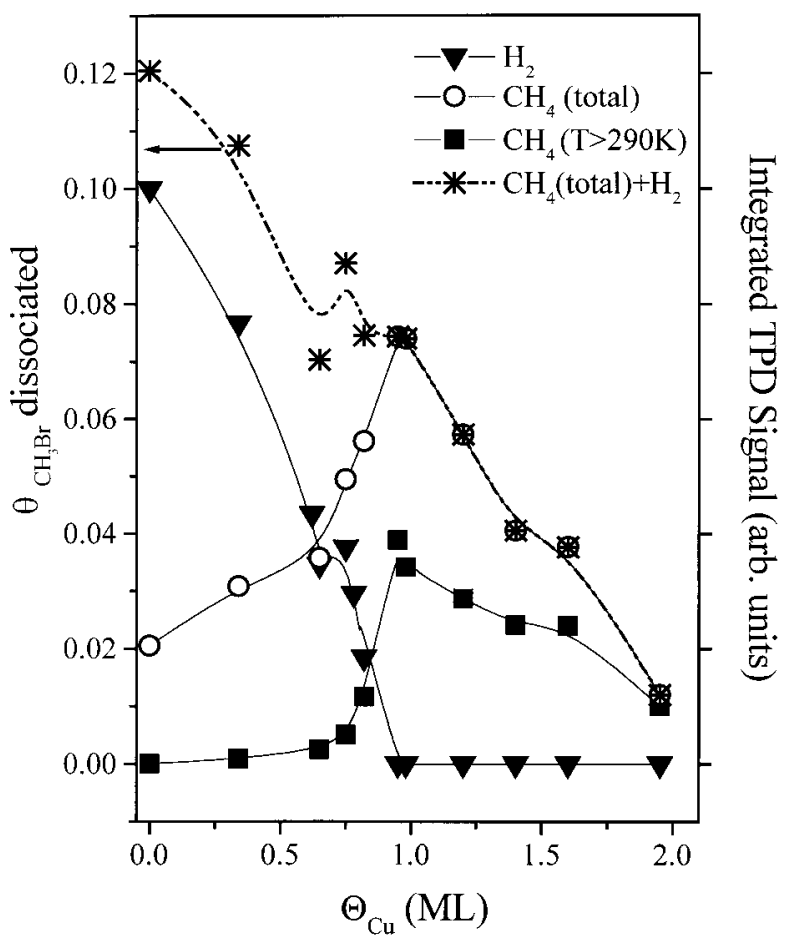

Figure 7. Extent of $\mathrm{CH}_{3} \mathrm{Br}$ fragmentation $\left(\theta=\mathrm{CH}_{3} \mathrm{Br} / \mathrm{Ru}(001)=0.22\right.$ \pm 0.02 at $1 \mathrm{ML})$ as a function of copper coverage, reflected by the integrated area under the hydrogen $(m / e=2)$ and methane $(m / e=16)$ $\Delta p$ TPD signals shown in Figure 6.

$\Delta \varphi$ TPD spectra at $\theta_{\mathrm{Cu}}>0.8 \mathrm{ML}$ (Figure 5) reveal a monotonic increase of the work function before and during the desorption of methane around $370 \mathrm{~K}$. This slow increase can be interpreted as the contribution of partial (diminishing) decomposition of the methyl and its products that results in the accumulation of hydrogen and possibly carbon atoms on the surface. The production of methane from the recombination of methyl radicals and hydrogen atoms was previously reported to take place on $\mathrm{Cu}(110)^{46}$ around $380 \mathrm{~K}$, in good agreement with the $370 \mathrm{~K}$ peak temperature observed in Figure 6. The recombination reaction to form methane is a second-order reaction that should shift to lower temperatures with increasing methyl radical and atomic hydrogen density. However, as seen in Figure 6, with decreasing copper coverages a clear shift to higher temperatures is observed with a common leading edge. This reaction scheme, therefore, is not consistent with a simple elementary second-order kinetics. It can, however, be rationalized as a pseudo-first-order reaction with excess methyl radical concentration. The hydrogen is apparently produced by dehydrogenation of the fraction of the methyl adsorbates as the ratelimiting step followed by a fast hydrogen-methyl recombination reaction to form methane. Since the rate constants for hydrogen recombination and methyl radical hydrogenation are comparable, ${ }^{46}$ the absence of hydrogen desorption indicates that its concentration is negligible throughout the course of the reaction and supports the above interpretation. When copper coverage approaches $2 \mathrm{ML}$, less hydrogen is produced because of passivation of the surface toward methyl dissociation, as discussed above.

X-ray photoelectron spectroscopy (XPS) ${ }^{16}$ and photoemission of adsorbed xenon $(\mathrm{PAX})^{17}$ studies of the $\mathrm{Cu} / \mathrm{Ru}(001)$ system have revealed strong electronic perturbations at the first copper monolayer coverage range. These perturbations are held responsible for the higher reactivity of the $\mathrm{Cu}(1 \mathrm{ML}) / \mathrm{Ru}(001)$ relative to the $\mathrm{Cu}(2 \mathrm{ML}) / \mathrm{Ru}(001)$. The ability of the transition metal to chemically activate noble metal atoms is well-known in heterogeneous catalysis ${ }^{15 a}$ and has recently been discussed theoretically on the basis of $\mathrm{d}$ electron occupation using density functional theory. ${ }^{15 \mathrm{~b}}$ For example, the rate of cyclohexene dehydrogenation is 6-fold-enhanced on the $\mathrm{Au}(1 \mathrm{ML}) / \mathrm{Pt}(100)$ surface compared to the $\mathrm{Pt}(100)$ surface. ${ }^{14}$ Coverages of $2 \mathrm{ML}$ of $\mathrm{Au}$ on $\mathrm{Pt}(100)$ were found, however, to deactivate the surface. In a similar way, our results indicate that $1 \mathrm{ML}$ of $\mathrm{Cu}$ is not sufficient to deactivate the $\mathrm{Ru}(001)$ surface for both $\mathrm{CH}_{3} \mathrm{Br}$ and $\mathrm{CH}_{3}$ dissociation. Only upon second-layer $\mathrm{Cu}$ deposition is the $\mathrm{Ru}$ surface practically passivated (besides dissociation at defect sites). Copper deposition beyond 2 ML (checked specifically for coverages up to $5 \mathrm{ML}$ ) causes further increase of the surface work function by $0.08 \mathrm{~V}$, toward that of $\mathrm{Cu}(111),{ }^{25 \mathrm{a}}$ with no substantial change in the surface reactivity. We conclude that the surface work function, which responds to bond polarization at the first monolayer regime, is not sensitive enough as a probe of surface reactivity beyond $1 \mathrm{ML}$ of deposition.

It is worthwhile to compare the methyl chemistry on $\mathrm{Cu}(1$ $\mathrm{ML}) / \mathrm{Ru}(001)$ with that on $\mathrm{Cu}(110)^{46}$ and $\mathrm{Cu}(111),{ }^{31,47}$ where it was prepared from $\mathrm{CH}_{3} \mathrm{I}$ dissociation. A detailed study of these surfaces have found methyl radicals to be stable up to $400 \mathrm{~K}$, where they disproportionate to form mainly methane and ethylene with the same first-order kinetics and the same desorption rate, with a peak desorption temperature around 460 $\mathrm{K}$. The rate-determining step is the dissociation of $\mathrm{CH}_{3}$ to $\mathrm{CH}_{2}$ and $\mathrm{H}$. At higher methyl coverages ethane $\left(\mathrm{C}_{2} \mathrm{H}_{6}\right)$ is also produced around $450 \mathrm{~K}$ by $\mathrm{CH}_{3}$ coupling with pronounced second-order kinetics features. This channel has a threshold methyl coverage $\theta_{\mathrm{CH} 3}>0.015 .{ }^{46}$

Methyl radical dissociation was shown to strongly depend on the hydrogen surface coverage. When a $\mathrm{Cu}(110)$ surface covered by adsorbed methyl is exposed to deuterium atoms (produced by a hot filament), most of the methyl radicals have desorbed around $380 \mathrm{~K}$ as $\mathrm{CH}_{3} \mathrm{D},{ }^{46}$ prior to the methyl decomposition, which takes place at $T>400 \mathrm{~K}$. In the present study, at $\theta_{\mathrm{Cu}}$ in the range $1-2 \mathrm{ML}$, the hydrogen atoms are supplied by methyl dehydrogenation either on the Ru sites, which are exposed through defects in the copper layer, or on the $\mathrm{Cu}(1 \mathrm{ML}) / \mathrm{Ru}(001)$ terraces, as a result of methyl dissociation. Both lead to methyl hydrogenation to form methane around $370 \mathrm{~K}$, similar to the chemistry on $\mathrm{Cu}(110) .{ }^{46}$

3.2.2. $\mathrm{CH}_{3} / \mathrm{Cu}(1 \mathrm{ML}) / \mathrm{Ru}(001)$ vs $\mathrm{CH}_{3} / \mathrm{Cu}(2 \mathrm{ML}) / \mathrm{Ru}(001)$. Unlike $\mathrm{CH}_{3} \mathrm{I}$, methyl bromide does not dissociate at all on $\mathrm{Cu}(111),{ }^{32,33}$ and only a small fraction dissociates on $\mathrm{Cu}(2 \mathrm{ML}) /$ $\mathrm{Ru}(001)$. Consequently, the chemistry of methyl on these surfaces (in the absence of coadsorbed hydrogen atoms) cannot be studied by simple thermal excitation. To produce a high density of methyl radicals on the surface, we had to apply other means to dissociate the parent molecule. This was achieved by exposing the $\mathrm{CH}_{3} \mathrm{Br} / \mathrm{Cu}(2 \mathrm{ML}) / \mathrm{Ru}(001)$ system to UV light from a xenon lamp $(450 \mathrm{~W})$ with a wavelength range of $230-420$ nm. Photodissociation of $\mathrm{CH}_{3} \mathrm{Br}$ to $\mathrm{CH}_{3}$ and $\mathrm{Br}$ is rather facile. ${ }^{33,39}$ Adsorbed methyl groups on $\mathrm{Cu}(2 \mathrm{ML}) / \mathrm{Ru}(001)$ were thus formed at an equivalent coverage of 0.18 of the initial 1 ML of methyl bromide and then react to form methane and desorb around $460 \mathrm{~K}$. This is similar to the outcome of the thermal dissociation of $\mathrm{CH}_{3} \mathrm{I}$ on $\mathrm{Cu}(111) .{ }^{31}$ Halides at low coverages do not affect the rate of methane formation and its desorption temperature from copper surfaces. ${ }^{46,47}$ The influence of the underlying $\mathrm{Ru}$ on the reaction between methyl fragments on copper can be studied most conveniently by a comparison between the chemistry on $\mathrm{Cu}(1 \mathrm{ML}) / \mathrm{Ru}(001)$ to that on $\mathrm{Cu}(2$ $\mathrm{ML}) / \mathrm{Ru}(001)$. 


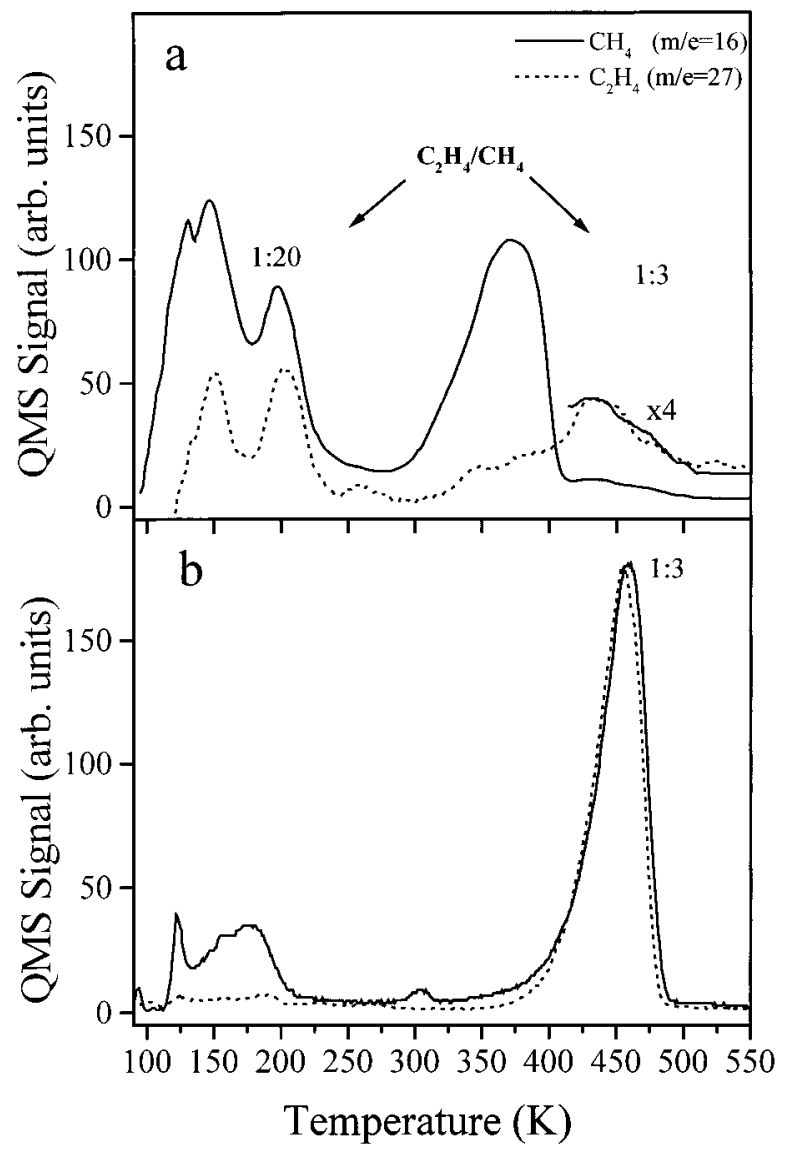

Figure 8. $\Delta p$ TPD spectra of $\mathrm{CH}_{4}$ (solid line) and $\mathrm{C}_{2} \mathrm{H}_{4}$ (dotted line) (a) after exposing $\mathrm{Cu}(0.95 \mathrm{ML}) / \mathrm{Ru}(001)$ surface to $6 \mathrm{~L}$ of $\mathrm{CH}_{3} \mathrm{Br}$. The tail above $400 \mathrm{~K}$ is 4 -fold-magnified. (b) After covering a $\mathrm{Cu}(2 \mathrm{ML}$ )/ $\mathrm{Ru}(001)$ surface by $1 \mathrm{ML}$ of $\mathrm{CH}_{3} \mathrm{Br}$ (4L exposure) followed by 24 min of broad-band UV $(230-420 \mathrm{~nm})$ irradiation from a $450 \mathrm{~W}$ Xe lamp.

In Figure 8 we compare the temperature-programmed methane production (solid lines) from $\mathrm{Cu}(0.95 \mathrm{ML}) / \mathrm{Ru}(001)$ (Figure $8 \mathrm{a})$ to that from $\mathrm{Cu}(2 \mathrm{ML}) / \mathrm{Ru}(001)$ (Figure 8b). Methyl fragments are generated by thermal dissociation of the parent $\mathrm{CH}_{3} \mathrm{Br}$ molecule on $\mathrm{Cu}(0.95 \mathrm{ML}) / \mathrm{Ru}(001)$ and via photochemical decomposition on $\mathrm{Cu}(2 \mathrm{ML}) / \mathrm{Ru}(001)$. A small fraction of the methyl fragments react through a competing channel to form ethylene, as shown in the dotted lines. No $\mathrm{C}_{2} \mathrm{H}_{6}$ molecules are produced on both copper-covered surfaces. This can be explained by the need for higher methyl coverage in order to initiate a methyl coupling reaction to form ethane, as was found on $\mathrm{Cu}(111)^{31,47}$ and $\mathrm{Cu}(110) .{ }^{46}$

Several important differences are noted in the methyl reactivity on the two copper-covered surfaces. On $\mathrm{Cu}(0.95 \mathrm{ML}) /$ $\mathrm{Ru}(001)$ (Figure 8a) the production and desorption peak of $\mathrm{CH}_{4}$ $(370 \mathrm{~K})$ appears at lower temperature and it does not overlap the minor $(\sim 0.003 \mathrm{ML})$ ethylene desorption peak. The desorption profiles of methane and ethylene at $460 \mathrm{~K}$ from $\mathrm{Cu}(2 \mathrm{ML}) /$ $\mathrm{Ru}(001)$, however, exactly overlap, as seen in Figure 8b. On both copper coverages the ethylene/methane ratio above $400 \mathrm{~K}$ is 1:3. This observation suggests that at these temperatures methane and ethylene are produced via the same mechanism: methyl disproportionation on top of the copper terraces, as was shown before to be the mechanism on $\mathrm{Cu}(110)$ and $\mathrm{Cu}(111){ }^{31,46,47}$ The intensity ratio of 1:20 for $\mathrm{C}_{2} \mathrm{H}_{4} / \mathrm{CH}_{4}$ observed at the methane desorption peak near $200 \mathrm{~K}$ (Figure 8a) indicates that the mechanism that leads to ethylene production at this temperature range is different; ethylene was shown to be formed on copper

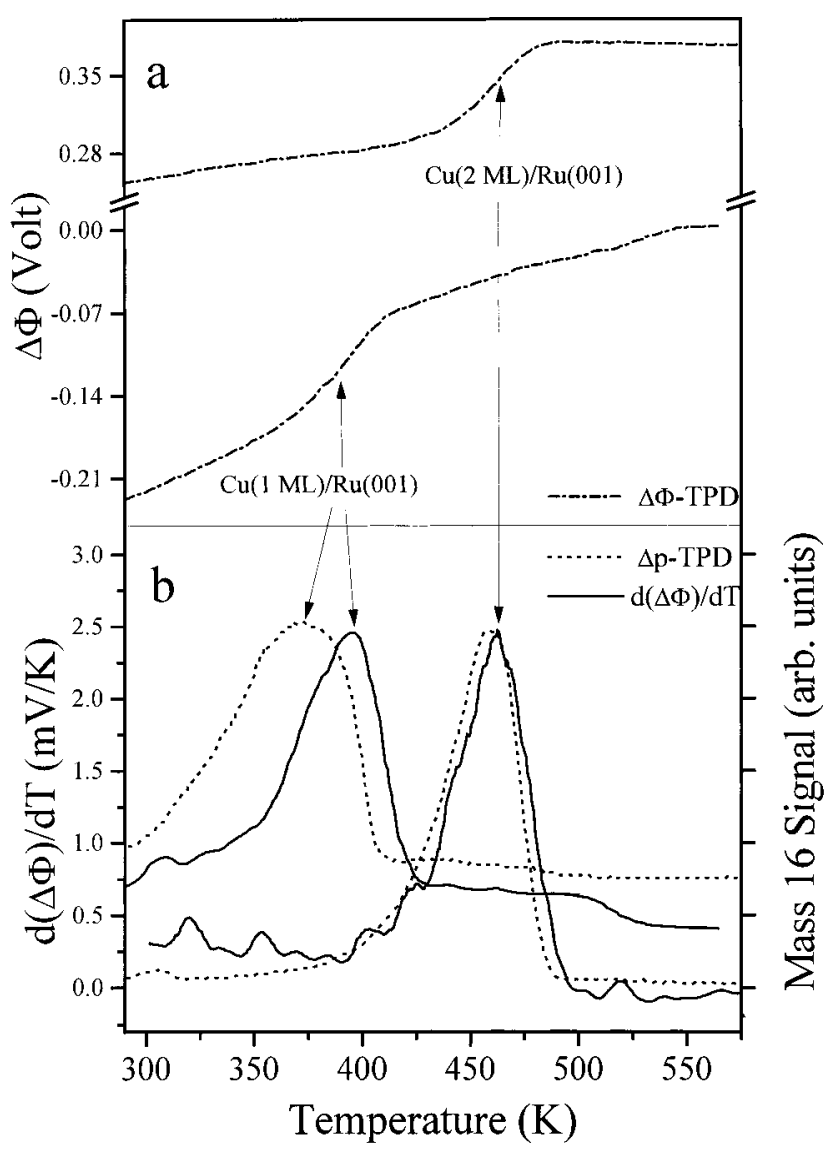

Figure 9. (a) $\Delta \varphi$ TPD (dashed-dotted lines) and (b) $\Delta p$ TPD (dotted lines) and $\mathrm{d}(\Delta \varphi) / \mathrm{d} T$ (solid lines) spectra after exposing $\mathrm{Cu}(1 \mathrm{ML}) /$ $\mathrm{Ru}(001)$ surface to $6 \mathrm{~L}$ of $\mathrm{CH}_{3} \mathrm{Br}$. The same is also measured on a $\mathrm{Cu}(2 \mathrm{ML}) / \mathrm{Ru}(001)$ surface covered by $1 \mathrm{ML}$ of $\mathrm{CH}_{3} \mathrm{Br}$ (4 L exposure) and followed by 24 min of broad-band UV $(230-420 \mathrm{~nm})$ irradiation from a $450 \mathrm{~W}$ Xe lamp.

surfaces also by methylene coupling $\left(2 \mathrm{CH}_{2} \rightarrow \mathrm{C}_{2} \mathrm{H}_{4}\right)$ around 200-230K. ${ }^{46,48}$ Methylene groups may be formed at copper step edges where higher reactivity toward $\mathrm{CH}_{3}$ dehydrogenation is expected with subsequent "spill over" on top of the copper terraces. This channel is gradually eliminated upon second copper layer deposition (not shown). Finally, we note the small methane peak produced on $\mathrm{Cu}(2 \mathrm{ML}) / \mathrm{Ru}(001)$, as seen in Figure $8 \mathrm{~b}$ around $300 \mathrm{~K}$ without any ethylene formation. This peak is attributed to a recombination of hydrogen (produced at surface defects) with methyl radicals. ${ }^{46}$ Production of methane at the same temperature was previously observed after photochemical decomposition of $\mathrm{CH}_{3} \mathrm{Br}$ on $\mathrm{Cu}(10 \mathrm{ML}) / \mathrm{Ru}(001)$ as well. ${ }^{39}$

The effect of the underlying ruthenium atoms on the reaction of methyl species on top of the copper terraces can also be studied by measuring the work function change during methane formation and desorption between 300 and $500 \mathrm{~K}$, employing a $\Delta \varphi$ TPD mode. In Figure $9 \mathrm{a}, \Delta \varphi$ measurements during methane production on $\mathrm{Cu}(2 \mathrm{ML}) / \mathrm{Ru}(001)$ are shown for photochemically produced $\mathrm{CH}_{3}$ (upper curve) and for thermally produced $\mathrm{CH}_{3}+\mathrm{H} / \mathrm{Cu}(1 \mathrm{ML}) / \mathrm{Ru}(001)$ (lower curve). Before and after the methane desorption, only a small change in the work function is observed on the $\mathrm{Cu}(2 \mathrm{ML}) / \mathrm{Ru}(001)$ surface. In contrast, in the $\mathrm{Cu}(1 \mathrm{ML}) / \mathrm{Ru}(001)$ case, a continuous increase in the work function of about $0.7 \mathrm{mV} / \mathrm{K}$, prior to desorption, is observed. This rate of increase scales with the amount of methane that desorbs around $370 \mathrm{~K}$ (not shown). Therefore, we attribute this increase to methyl fragmentation on the copper monolayer followed by accumulation of hydrogen atoms on the surface. This hydrogen, however, is not in high enough density 
to recombine and desorb as $\mathrm{H}_{2}$ at temperatures below the desorption of methane.

A comparison of the $\Delta p$ TPD and the $\mathrm{d}(\Delta \varphi) / \mathrm{d} T$ spectra is shown in Figure 9b. For the $\mathrm{Cu}(2 \mathrm{ML}) / \mathrm{Ru}(001)$ case there is a very good overlap between the two spectra. This is not surprising, considering that we actually follow the ratedetermining step, which is methyl dissociation $\left(\mathrm{CH}_{3} \rightarrow \mathrm{CH}_{2}+\right.$ H). ${ }^{46,47}$ The reactions of methylene insertion and methyl hydrogenation were found to be considerably faster than methyl dissociation on $\mathrm{Cu}(110) .{ }^{46}$ Therefore, further decomposition of the methylene fragments must take place simultaneously with the methyl fragmentation without affecting the measured work function change.

The work function increases by $0.12 \mathrm{~V}$ upon the removal of methyl species from $\mathrm{Cu}(2 \mathrm{ML}) / \mathrm{Ru}(001)$. On the basis of the integrated area under the corresponding methane $\Delta p$ TPD peak, the photochemically generated methyl coverage reached $\mathrm{CH}_{3} /$ $\mathrm{Cu}=0.04 \mathrm{ML}(0.18$ of an initial $1 \mathrm{ML}$ of methyl bromide). Simple calculation based on the Helmholtz equation, $\Delta \varphi=$ $4 \pi N \mu_{0}$, where $N$ is the surface methyl density and $\mu_{0}$ is the isolated methyl dipole moment, provides an estimate of the isolated adsorbed methyl dipole moment of $\mu_{0}=0.48 \mathrm{D}$ (1 D $=3.34 \times 10^{-30} \mathrm{C} \mathrm{m}$ ). The justification to use this simplified model stems from the low coverage and insignificant dipoledipole interaction between the methyl adsorbates.

Unlike the $\mathrm{Cu}(2 \mathrm{ML}) / \mathrm{Ru}(001)$ surface, at the lower coverage of $\mathrm{Cu}(1 \mathrm{ML}) / \mathrm{Ru}(001)$, the $\mathrm{d}(\Delta \varphi) / \mathrm{d} T$ spectrum does not overlap the $\Delta p$ TPD. The $\mathrm{d}(\Delta \varphi) / \mathrm{d} T$ peak shifts to higher temperatures by $25 \mathrm{~K}$ with respect to the $\Delta p$ TPD spectrum. A similar peak temperature shift $(26 \mathrm{~K})$ is also observed for $\mathrm{Cu}(1.5 \mathrm{ML}) /$ $\mathrm{Ru}(001)$. The origin of this temperature shift is not well understood. Taking into account the low concentration of methyl species, we exclude dipole-dipole interactions as the origin of this lack of overlap between the two spectra. The enhanced dissociation of the methyl fragments prior to methane desorption, which results in the sudden rise in surface coverage of methylene and hydrogen species, is not a feasible explanation as well. This is due to the absence of detectable ethylene desorption at these temperatures (see Figure 8a), expected to reflect the presence of methylene fragments on the surface. Higher density of carbon deposits may explain the observed difference. Further investigation of this issue is required.

3.3. $\mathrm{CH}_{2} / \mathbf{C u}(\mathbf{0}-\mathbf{1 M L}) / \mathbf{R u}(\mathbf{0 0 1})$. The dehydrogenation pathway of $\mathrm{CH}_{3} \mathrm{Br} / \mathrm{Ru}(001)^{29}$ was shown to correlate well with the suggested scheme for $\mathrm{CH}_{3} \mathrm{I} / \mathrm{Ru}(001) .{ }^{28}$ By combination of the work function change and $\Delta p$ TPD data, additional insight could be gained. Similar information has been obtained for the coppercovered ruthenium. A comparison between the hydrogen desorption signal obtained at various copper coverages (Figure 10a) and their corresponding $\Delta \varphi$ TPD spectra (Figure 10b) is presented. The $\mathrm{CH}_{2}$ fragments that are left on the surface in the presence of copper at temperatures higher than $210 \mathrm{~K}$ display a different $\Delta \varphi$ TPD profile during their dissociation than on the clean $\mathrm{Ru}(001)$ surface. Between the clean and 0.45 ML copper-covered $\mathrm{Ru}(001)$ surfaces a peak emerges in the $\Delta \varphi \mathrm{TPD}$ between 280 and $320 \mathrm{~K}$. The dissociation pathway changes already at very low copper coverages $\theta_{\mathrm{Cu}}=0.11$, and at least part of it occurs at sites that are localized around the copper step edge boundary (sites b in Figure 2). At the same time, the high-temperature $\Delta p$ TPD peak of hydrogen near $310 \mathrm{~K}$ decreases significantly. This hydrogen peak is attributed to a combination of ethylidine $\left(\mathrm{CCH}_{3}\right)$ dissociation and recombinative desorption of hydrogen. ${ }^{28,29}$ The faster decay of this $310 \mathrm{~K}$ $\Delta p$ TPD peak relative to the $280 \mathrm{~K}$ peak may be explained by

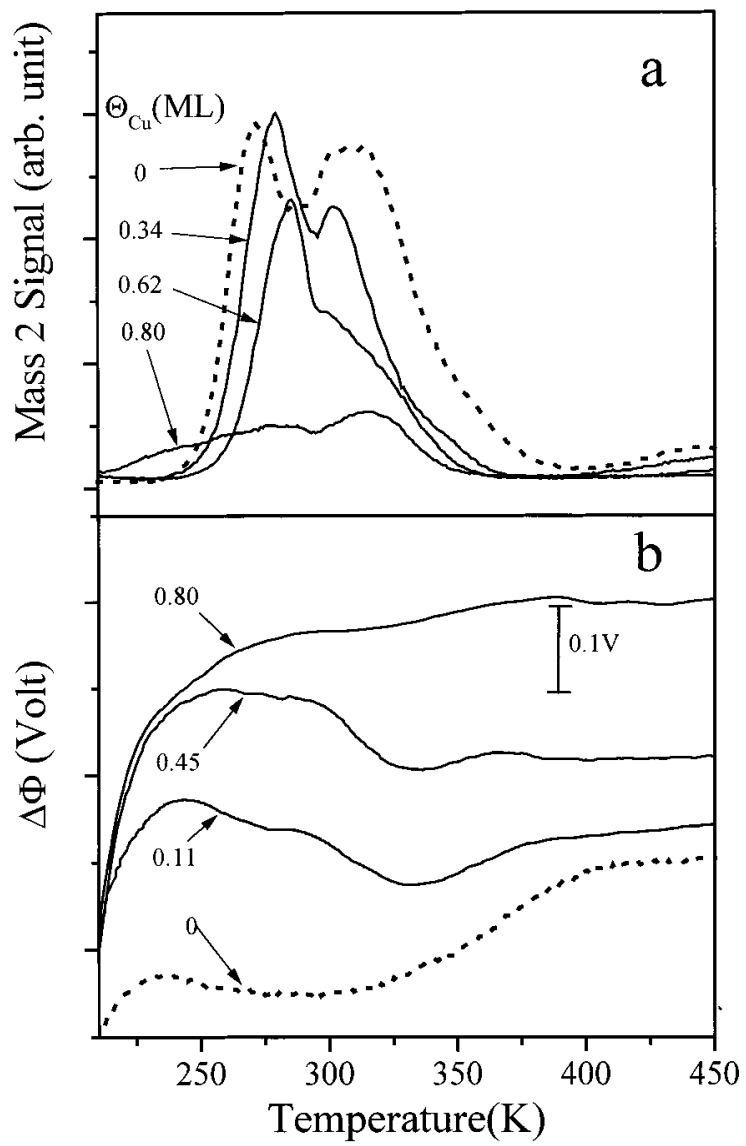

Figure 10. Comparison between (a) $\Delta p$ TPD of hydrogen and (b) $\Delta \varphi$ TPD after exposing $\mathrm{Ru}(001)$ surface covered by the indicated copper coverage $(0-0.80 \mathrm{ML})$ to $6 \mathrm{~L}$ of $\mathrm{CH}_{3} \mathrm{Br}$. For reasons of clarity, the $\Delta \varphi$ TPD spectra are shifted upward without a true representation of the $\Delta \varphi$ values.

the lower rate of ethylidine formation from recombination between two $\mathrm{CH}_{2}$ groups ${ }^{28,29}$ as the copper coverage increases. This is consistent with the restricted diffusion of the $\mathrm{CH}_{2}$ fragments due to their capture at the step edges of the growing copper layers. ${ }^{22}$ Finally, the $\Delta \varphi$ TPD profile around $300 \mathrm{~K}$ suddenly changes at about $\theta_{\mathrm{Cu}}=0.8 \mathrm{ML}$, which correlates well with the onset of methane formation detected at $370 \mathrm{~K}$ in the $\Delta p$ TPD spectra shown in Figure 6.

\section{Conclusions}

$\mathrm{CH}_{3} \mathrm{Br} / \mathrm{Cu} / \mathrm{Ru}(001)$ is an interesting model system to investigate the chemistry of methyl halides on bimetalic catalysts for the following reasons. (a) $\mathrm{Cu}$ is immiscible in $\mathrm{Ru}$, and its overlayer structure is well established in the coverage range $\theta_{\mathrm{Cu}}$ $=0-4 \mathrm{ML}$. (b) The different reactivity of $\mathrm{CH}_{3} \mathrm{Br}$ on singlecrystal copper (no dissociation) vs $\mathrm{Ru}(001)$ surface $(55 \%$ dissociation) enables the gradual change in reactivity with growing copper coverage.

The chemistry of $\mathrm{CH}_{3} \mathrm{Br}$ on $\mathrm{Cu} / \mathrm{Ru}(001)$ has been studied utilizing work function change $(\Delta \varphi)$ and TPD measurements. A decrease in work function at the completion of $1 \mathrm{ML}$ of $\mathrm{CH}_{3} \mathrm{Br}$ of $2.15 \pm 0.02 \mathrm{eV}$ and $1.33 \pm 0.05 \mathrm{eV}$ have been measured, respectively, for $\mathrm{Ru}(001)$ and $\mathrm{Cu}(2 \mathrm{ML}) / \mathrm{Ru}(001)$ held at $82 \mathrm{~K}$. Methyl bromide does not dissociate upon adsorption on the clean or the copper-covered ruthenium surfaces, and it is bound with the bromine down at coverages below the completion of the first monolayer.

Copper inhibits the dissociation of $\mathrm{CH}_{3} \mathrm{Br}$ on $\mathrm{Ru}(001)$ and modifies the dehydrogenation pathway of the methyl fragment. 
As copper atoms gradually block ruthenium sites, a decrease in the extent of methyl dehydrogenation is observed. Thus, the accumulation of methyl fragments gradually enhances the formation and desorption of methane on account of hydrogen.

In the copper coverage range $0.8-0.95 \mathrm{ML}$, adsorbed hydrogen and methyl coexist on the surface in the temperature range $230-280 \mathrm{~K}$, as revealed by the $\Delta p$ TPD of both hydrogen and methane. It indicates that the methyl species "survive" on the $\mathrm{Cu} / \mathrm{Ru}(001)$ surface at a temperature range where it would have been completely dehydrogenated on the bare ruthenium surface. Near the completion of one copper monolayer, hydrogen desorption completely terminates. It marks a significant decrease in $\mathrm{CH}_{3}$ dehydrogenation rate due to insufficient area of bare ruthenium active sites.

In contrast to the information obtained from work function change measurements, reactivity of the first pseudomorphic copper layer is significant toward methyl bromide and methyl dissociation. At $\theta_{\mathrm{Cu}}$ in the range $1-2 \mathrm{ML}$ with $1 \mathrm{ML}$ of $\mathrm{CH}_{3} \mathrm{Br}$ on top, $\Delta \varphi$ TPD measurements indicate a continuous increase at temperatures below any hydrogen or methane desorption around $370 \mathrm{~K}$. This work function increase is attributed to a continuous decomposition of the methyl and its fragments, becoming the hydrogen source for the methyl-hydrogen recombination reaction to form methane. Upon completion of the second copper layer the $\mathrm{Ru}(001)$ surface is passivated and only 0.06 out of a monolayer of $\mathrm{CH}_{3} \mathrm{Br}$ dissociates, probably because of defects.

Acknowledgment. We thank Ch. Ammer and H. Neddermeyer for providing us the STM image shown in Figure 1. This research has been partially supported by a grant from G.I.F., the German-Israeli Foundation for Scientific Research and Development, The Israel Science Foundation, and the James Franck Program. The Farkas Center for Light Induced Processes is supported by the Bundesministerium für Forschung und Technologie and the Minerva Gesellschaft für die Forschung $\mathrm{mbH}$.

\section{References and Notes}

(1) Sinfelt, J. H. Bimetallic catalysts: discoveries, concepts and applications; Wiley: New York, 1983.

(2) Sinfelt, J. H. Acc. Chem. Res. 1977, 10 and references therein.

(3) Bond, G. C.; Turnham, B. D. J. Catal. 1976, 45, 128.

(4) Wu, X.; Gerstein, B. C.; King T. S. J. Catal. 1990, 121, 271.

(5) Vannice, M. A. J. Catal. 1975, 37, 449.

(6) Vannice, M. A. J. Catal. 1975, 37, 462.

(7) Pötschke, G.; Schröder, J.; Günther, C.; Hwang, R. Q.; Behm. R. J. Surf. Sci. 1991, 251/252, 592.

(8) (a) Günther, C.; Vrijmoeth, J.; Hwang, R. Q.; Behm, R. J. Phys. Rev. Lett. 1995, 74, 754. (b) Pötschke, G.; Behm, R. J. Phys. Rev. Lett. 1991, 44, 1442.

(9) Ammer, Ch. Private communication. (b) Ammer, Ch.; Meinel, K.; Wolter, H.; Beckmann, A.; Neddermeyer, H. Surf. Sci. 1997, 375, 302.

(10) Yates, J. T., Jr.; Peden, C. H. F.; Goodman, D. W. J. Catal. 1985 $94,576$.
(11) Park, C.; Bauer, E.; Popa, H. Surf. Sci. 1987, 187, 86.

(12) Vickerman, J. C.; Christmann, K.; Ertl, G. J. Catal. 1981, 71, 175.

(13) Campbell C. T. Annu. Rev. Phys. Chem. 1990, 41, 775.

(14) Sachtler, J. W. M.; Biberian, J. P.; Somorjai, G. A.Surf. Sci. 1981, 110,43 .

(15) Goodman, D. W. J. Phys. Chem. 1996, 100, 13090 and references therein. (b) Besenbacher, F.; Chorkendorff, I.; Clausen, B. S.; Hammer, B.; Molenbroek, A. M.; Nørskov, J. K.; Stensgaard, I. Science 1998, 279, 1913.

(16) Rodriguez, J. A.; Campbell, R. A.; Corneille, J.S; Goodman, D. W. Chem. Phys. Lett. 1991, 180, 139.

(17) Kim, K. S.; Sinfelt, J. H.; Eder, S.; Market, K.; Wandelt, K. J. Phys. Chem. 1987, 91, 2337.

(18) Wandelt, K. In Physics and Chemistry of Alkali Metal Adsorption; Bonzel H. P., Bradshaw A. M., Ertl G., Eds.; Elsevier: Amsterdam, 1989; p 25.

(19) Kalki, K.; Pennemann, B.; Schröder, U.; Heichler, W.; Wandelt, K. Appl. Surf. Sci. 1991, 48/49, 59.

(20) Avouris, P.; Lyo, I-W.; Walkup, R. E. J. Vac. Sci. Technol. B 1994, 12, 1447 .

(21) Crommie, M. F.; Lutz, C. P.; Eigler, D. M. Nature 1993, 363, 524.

(22) Brown, D. E.; Sholl, D. S.; Skodje, R. T.; George, S. M. Chem. Phys. 1996, 205, 23.

(23) Christmann, K.; Ertl, G.; Shimizu, H. J. Catal. 1980, 61, 397.

(24) Houston, J. E.; Peden, C. H. F.; Blair, D.S; Goodman, D. W. Surf. Sci. 1986, 167, 427 .

(25) Wolter, H.; Schmidt, M.; Wandelt, K. Surf. Sci. 1993, 298, 173. (b) Campbell, C. T. Annu. Rev. Phys. Chem. 1990, 41, 775.

(26) Sakakini, B.; Swift, A. J.; Vickerman, J. C.; Harendt, C.; Christmann, K. J. Chem. Soc., Faraday Trans. 1 1987, 83, 1975.

(27) Dubois, L. H.; Bent, B. E.; Nuzzo, R. G. In Surface Reactions; Madix, R. J., Ed.; Springer Series in Surface Science 34; Springer-Verlag: Berlin, 1994; p 135.

(28) Zhou, Y.; Henderson, M. A.; Feng, W. M.; White, J. M Surf. Sci. 1989, 224,386

(29) Livneh, T.; Asscher, M. J. Phys. Chem. 1997, B101, 7505.

(30) Livneh, T.; Asscher, M. Langmuir 1998, 14 (6), 1348.

(31) Lin, J.-L.; Bent, B. E. J. Vac. Sci. Technol. 1992, 10 (4), 2202.

(32) Lin, J.-L.; Bent, B. E. J. Phys. Chem. 1992, 96, 8529.

(33) Lamont, C. L. A.; Conrad, H.; Bradshaw, A. M. Surf. Sci. 1993, 280,79 .

(34) Kawaguchi, T.; Hijikigawa, M.; Hayafuji, Y.; Ikeda, M.; Fukushima,

R.; Tomiie, Y. Bull. Chem. Soc. Jpn. 1973, 46, 53.

(35) Maschhoff, B. L.; Cowin, J. P. J. Chem. Phys. 1994, 101 (9), 8138.

(36) Redhead P. A Vacuum 1962, 12, 203.

(37) French, C.; Harrison, I. Surf. Sci. 1995, 342, 85.

(38) French, C.; Harrison, I. Surf. Sci. 1997, 387, 11.

(39) Roop, B.; Zhou, Y.; Liu, Z.-M.; Henderson, M. A.; Lloyd, K. G.; Campion, A.; White, J. M. J. Vac. Sci. Technol. 1989, A7, 2121.

(40) Handbook of Chemistry and Physics, 76th ed.; Lide, D. R., Ed.; CRC: Roca Raton, FL, 1995.

(41) Bange, K.; Dohl, R.; Grinder, D. E.; Sass, J. K. Vacuum 1983, 33 $(10-12), 757$.

(42) Goddard, P. J.; Lambert, R. M. Surf. Sci. 1977, 67, 180.

(43) Preyss, W.; Ebinger, H. D.; Fick, D.; Polenz, C.; Polivka, B.; Saier, V.; Veith, R.; Weindel, Ch.; Jänsch, H. J. Surf. Sci. 1997, 373, 33.

(44) Livneh, T.; Asscher, M. Submitted for publication.

(45) Goodman, D. W.; Yates, J. T., Jr.; Peden, C. H. F. Surf. Sci. 1985, $164,417$.

(46) Chiang, C.-M.; Wentzlaff, T. H.; Bent, B. E. J. Phys. Chem. 1992 96, 1836.

(47) Chiang, C.-M.; Bent, B. E Surf. Sci. 1992, 279, 79.

(48) Kovács, I.; Solymosy, F. J. Phys. Chem. B 1997, 101, 5397. 